\title{
It's not my job: Compensatory effects of procedural justice and goal setting on proactive preventive behavior
}

\author{
Run Ren ${ }^{1 *}$, Aneika L. Simmons ${ }^{2}$, Adam Barsky $^{3}$, Kelly E. See ${ }^{4}$ and Celile Itir Gogus ${ }^{5}$ \\ ${ }^{1}$ Guanghua School of Management, Peking University, Beijing, People's Republic of China, ${ }^{2}$ Department of Management \\ and Marketing, Sam Houston State University, Huntsville, TX, USA, ${ }^{3}$ Department of Management, University of \\ Melbourne, Parkville, VIC, Australia, ${ }^{4}$ Business School, University of Colorado Denver, Denver, CO, USA and ${ }^{5}$ Faculty \\ of Business Administration, Bilkent University, Ankara, Turkey \\ ${ }^{\star}$ Corresponding author. Email: renr@gsm.pku.edu.cn
}

(Received 17 March 2016; revised 18 September 2018; accepted 10 October 2018)

\begin{abstract}
In two experiments, we examined the function of procedural justice in signaling individuals' value to the group by arguing that individuals treated fairly are more likely to engage in proactive preventive behavior, a behavior that involves proactively revising or correcting the mistakes and intentional deceptions of coworkers. In addition, we extend Staw and Boettger's (1990) work on task revision and demonstrate that procedural justice and goal setting have compensatory effects, such that procedural justice can be combined with performance goals to reap the valuable aspects of goal setting while minimizing some of the unintended side-effects. Our findings also contribute to the ongoing discussion of the mixed effects of goal setting, as well as the effects of multiple goal assignment.
\end{abstract}

Keywords: technical goal setting; truth and deception; multiple goals; procedural justice; proactive preventive behavior

\section{Introduction}

Beyond reactive citizenship behaviors, such as compliance with norms and helping those who express need (e.g., Borman \& Motowidlo, 1993), proactive behavior of employees is also increasingly needed. Proactive behaviors are anticipatory actions initiated by employees to impact themselves and their environment and have been regarded as critical drivers of organizational effectiveness (Grant \& Ashford, 2008; Parker \& Collins, 2010). Proactive behavior has typically been understood as an attempt to make positive changes to promote the self or the organization (i.e., proactive promotive behavior), such as offering help without being asked (Rioux \& Penner, 2001), seeking feedback from and expressing promotive voice to supervisors (Ashford \& Cummings, 1985; LePine \& Van Dyne, 2001; Liang, Farh, \& Farh, 2012), and taking initiative on setting goals (Frese \& Fay, 2001).

While proactive behavior directed at promoting self or collective goals and enhancing status (i.e., from good to better) is thought to be essential for high performing organizations, other forms of proactive behavior directed at preventing the self or collective from harm (i.e., from wrong to right) may be equally important for maintaining the integrity of a firm. These latter behaviors can be thought of as proactive preventive behaviors and may include such actions as taking initiative to blow the whistle on illicit behavior (e.g., Gundlach, Douglas, \& Martinko, 2003), speaking up to ensure low quality, harmful, or unsafe products are not released to the public (i.e., prohibitive voice, Liang, Farh, \& Farh, 2012), and revising flawed or deceptive work 
by others (Staw \& Boettger, 1990). Indeed, the importance of proactive preventive behaviors is evidenced by their presence in large corporate scandals involving outright fraud in Enron and WorldCom (Brickey, 2003), and by their absence in unsustainable risk taking at Lehman Brothers (Rappaport \& Rapoport, 2010) and quality problems at Toyota (Cole, 2011). Although much research has been conducted to understand when and how employees will conduct proactive promoting behaviors, such as organizational citizenship behavior (e.g., Organ \& Ryan, 1995) and voice (e.g., Morrison, 2011), far less is known about proactive preventive behaviors which are relatively more challenging and involve more risk (e.g., correcting wrongdoing).

Employees look at the workplace environment to determine what is expected of them in terms of tasks and behaviors. In this way, organizations tend to regulate employee behavior through both formal goals or performance management and also informal norms or values (Shantz \& Latham, 2011; Kuvaas, Buch, \& Dysvik, 2016). Formal performance management and goal setting primarily define employees' in-role behaviors (Griffin, 1987), but proactive behaviors are usually not formally stated within job descriptions. As such, organizations must rely primarily on the help of informal norms and values to encourage employees' proactive behavior, especially in the domain of proactive preventive behaviors that involve correcting wrongdoing and require more initiative. One way in which an organization signals its norms and values to employees is through organizational justice, which has been found to be positively related to proactive behavior (for a review, see Van Dyne, Cummings, \& Parks, 1995), including organizational citizenship behavior (Moorman, Niehoff, \& Organ, 1993; Organ \& Moorman, 1993) and employee helping behavior (Yang, Mossholder, \& Peng, 2009). When employees perceive that they are treated fairly, they seem to broaden their work domain beyond their formally stated prescribed roles and view proactive behavior as part of their job responsibility (Parker, 2000), which might therefore spur more proactive preventive behavior.

The aim of the current investigation is to deepen understanding of when and why employees act proactively to protect themselves, the firm, and other stakeholders from potential harm. We draw on the group-value model of procedural justice (Tyler \& Blader, 2000) to argue that individuals look to justice information when expanding their prescribed roles to include proactive preventive behavior in the form of identifying and correcting the deceptive claims of others. We propose that employees consider the perceived level of procedural justice of decision makers as information regarding their value to the group. Such information will in turn expand or contract the domain in which individuals are willing to exercise discretionary effort and perform more proactively on behalf of the group (Tyler \& Blader, 2000). Thus, we expect that individuals who perceive a high level of procedural justice will be more likely to engage in proactive preventive behavior.

We also propose that procedural justice is especially likely to influence proactive preventive behavior when formal behavioral requirements concerning integrity are uncertain. We examine the role of goal setting, as goals and their associated rewards make salient to an employee the specific aspects of performance that are valued and required by the organization (Locke \& Bryan, 1969; Locke \& Latham, 1984; 1990; Kanfer \& Ackerman, 1989; Staw \& Boettger, 1990). When behavioral expectations of integrity are explicitly advocated through the type or content of goals, we propose that the informational value of procedural justice is reduced and its effect on proactive preventive behavior will therefore be attenuated. But when a goal is assigned that focuses on tasks other than integrity, such as a specific technical goal, a vague goal, or multiple goals, we argue that individuals who are treated fairly will have a broader view of their roles and responsibilities than those who are treated unfairly, and will therefore be more likely to perform proactive preventive behavior. Together, these arguments suggest that procedural justice will have a positive influence on proactive preventive behavior, although the influence may be confined to situations where behavioral expectations of integrity are uncertain. We test these proposed relations among procedural justice, goal content, and proactive preventive behavior in two experiments. 
By integrating procedural justice and goal setting as potentially compensatory mechanisms for influencing proactive preventive behavior, we contribute to the theoretical understanding of a critical but understudied domain of proactivity (e.g., Parker, 2000; Frese \& Fay, 2001; Rioux \& Penner, 2001; Parker, Williams, \& Turner, 2006; Grant \& Ashford, 2008; Parker \& Collins, 2010). In addition, our paper speaks to procedural justice scholars interested in how the group-value model (e.g., Tyler, 1989; Conlon, 1993; Tyler, Degoey, \& Smith, 1996; Restubog, Hornsey, Bordia, \& Esposo, 2008) and uncertainty-management model (Van den Bos \& Lind, 2002) operate in the domain of proactive preventive behaviors, which carry more risk and require more initiative than the more frequently studied proactive promotive behaviors. Finally, we contribute to the ongoing theoretical discussion about the mixed effects of goals, which focus attention on performance in some areas at the expense of others (Locke \& Bryan, 1969; Kanfer \& Ackerman, 1989; Shah \& Kruglanski, 2002; Locke \& Latham, 2009; Ordonez, Schweitzer, Galinsky, \& Bazerman, 2009). We investigate an approach by which goals can be combined with procedural justice to reap the valuable aspects of goal setting while minimizing some of the unintended negative side effects.

\section{Theory and Hypotheses}

\section{Proactive preventive behavior}

The overall domain of proactive behavior has been operationalized in many different ways, including, for example, selling issues (Dutton \& Ashford, 1993), seeking feedback (Ashford \& Cummings, 1983), breaking rules (Morrison, 2006), revising tasks (Staw \& Boettger, 1990), and expanding roles (Nicholson, 1984). In their review of the topic, Grant and Ashford (2008) define proactive behavior as 'anticipatory action that employees take to impact themselves and/or their environments' (p. 8). Compared with reactive behavior, proactive behavior is future-focused (Frese \& Fay, 2001) and intends to have a discernible impact on the actor and/or the environment (Grant, 2007). More importantly, proactivity is not the same as pro-social or extra-role behavior. Indeed, some proactive behavior may be antisocial, such as an individual who devises and executes a plan to steal from a company. In addition, with ambiguity in the specification of prescribed activities, a proactive behavior may be in-role or extra-role depending on how they are construed by the employee (Grant \& Ashford, 2008). An employee can proactively find a new way to perform the prescribed job more efficiently. As discussed later, it is the effect of justice on the conceptualization of proactive behavior as being 'in-role' that increases its likelihood in the workplace.

Within the organizational literature, research has tended to focus on proactive behaviors which may promote (e.g., Ashford, Blatt, \& VandeWalle, 2003) or harm (e.g., Spector \& Fox, 2002) the actor, other people, or the collective. Indeed, employees are often expected not only to perform effectively within their narrowly prescribed role but also to go beyond their role expectations or monitor and correct the performance of colleagues and superiors. For example, when providing a colleague feedback on a research paper, one may make technical corrections, such as grammatical errors or typos, before sending the paper to a journal, and therefore help to reduce errors and improve the quality of the project. Such feedback is likely to be promotive. Alternatively, the same coauthor may identify distortions of data or ensure that content and ideas taken from others are credited appropriately. Such actions are more prevention-focused, as decisions to rectify such errors concern about the truthfulness of content, particularly if the recipient of the deceptive content can be harmed by relying on it. Research on such proactive preventive behavior is as critical as that on proactive promotive behaviors, if not more so, as the consequence of not proactively performing such preventive behavior could be severe. As previously mentioned, the tragedy of Toyota's quality problems with regard to unintended acceleration issues coupled with floor mat problems (Cole, 2011) could have been avoided, if a Toyota employee conducted proactive preventive behavior by recognizing and reporting the problem. 
Research on proactive behavior has documented a variety of its antecedents. In their extensive review of the topic, Grant and Ashford (2008) specified three antecedents: accountability, ambiguity, and autonomy. Specific job-related factors such as work stressors, time pressure, and affective experiences (Fay \& Sonnentag, 2002; Fritz \& Sonnentag, 2009) have also been found to be positively associated with personal initiative and taking charge at work. Moreover, personal factors, such as proactive personality (Parker, Williams, \& Turner, 2006), control orientation (Fay \& Frese, 2001), and positive mood (Fritz \& Sonnentag, 2009) have been found to encourage employees' proactive behavior in different forms. Sonnentag (2003) further found that employees' recovery from daily work at night was positively related to their next day's proactive behavior such as personal initiative and pursuit of learning. It is also possible that personal factors could interact with situational factors to affect employees' proactive behavior, as noted by Grant and Ashford (2008). Yet all of the aforementioned research pertains primarily to proactive promotive behavior, whereas relatively less has been examined regarding the antecedents of proactive preventive behavior. In the few extant studies in this area, Sims and Keenan (1998) found that supervisor support, informal policies, and ideal values were related to external whistleblowing. Also, Staw and Boettger (1990) found in their experiments that accountability increased participants' task revision behavior.

\section{Procedural justice and proactive preventive behavior}

Procedural justice pertains to fairness of the process by which organizational outcomes are determined (Thibaut \& Walker, 1975). When people feel the process used to determine outcomes is fair, they are more willing to accept the decision (e.g., Greenberg, 1987), more satisfied with the procedure (e.g., Thibaut \& Walker, 1975), and more willing to remain in the group (e.g., Brockner, Tyler, \& Cooper-Schneider, 1992) and help the group (e.g., Tyler \& Degoey, 1995). The group-value model of procedural justice, which is derived from social identity theory (Tajfel, 1978; Tajfel \& Turner, 1986), suggests that the positive effects of procedural justice occur because fair process conveys identity-related information to the individual (Lind \& Tyler, 1988; Tyler \& Lind, 1992). This model assumes that people are concerned about their long-term relationship with organizations and authorities. A high level of procedural justice from decision-making authorities communicates information that the individual is a respected and valued member in the group (Lind \& Tyler, 1988; Tyler \& Lind, 1992). The group-value model further suggests that people feel pride in such membership and will care a great deal about the group (Tyler, 1989). This can lead to a desire to pay back to the group and the organization by engaging in organizational citizenship behaviors (Moorman, Blakely, \& Niehoff, 1998) and other behaviors that benefit the group, such as working overtime or helping in emergencies (O'Reilly \& Chatman, 1986; Restubog et al., 2008). In other words, group identification is 'psychologically rewarding' in and of itself (Tyler, 1989: 831). This is because groups provide not only material resources but also provide emotional support and a sense of belonging, which are important sources of selfvalidation (Festinger, 1954).

We argue that when procedural justice is high, individuals will engage in greater proactive preventive behavior. That is, when people believe that they are valued members of the group, they want to perform proactively to help achieve group goals. One way to do this is through job-crafting, which entails proactively changing the task and relational boundaries of their job (Wrzesniewski \& Dutton, 2001). This is feasible in many situations, because information about job boundaries, the meaning of work, and work identities are not often fully described in formal job requirements. Thus, in an effort to maintain their group membership, individuals who are treated fairly are likely to craft the job in a broader scope to include various behaviors that will benefit the group, including preventing wrong information from being released by identifying and correcting any misinformation of superiors or other colleagues. 
On the other hand, when individuals feel they are being treated unfairly by the organization or its decision-making authorities, the group-value model suggests that they will feel devalued in the group and consequently may dis-identify with the group (Lind \& Tyler, 1988; Tyler \& Lind, 1992). Such individuals are, in turn, less willing to conduct desirable behaviors toward the group. Instead, they are likely to define their jobs more narrowly and only perform the minimum that is specified in their job description or their assigned task goals.

Based on the above discussion, we propose the following hypothesis:

Hypothesis 1: Procedural justice will be positively related to proactive preventive behavior.

\section{The interactive effect of procedural justice and goal setting}

In addition to the value of procedural justice as a way of encouraging proactive preventive behavior, organizations use other ways to communicate job expectations to employees. Indeed, the type of performance goals that are assigned to employees is a common way of providing explicit information to employees 'about what behavior is valued and appropriate' (Staw \& Boettger, 1990: 555). Despite the clear motivational and performance benefits of setting welldefined goals, empirical research also suggests that the lure of goal attainment can also lead to increased risk-taking (Knight, Durham, \& Locke, 2001; Larrick, Heath, \& Wu, 2009), dishonest reporting of performance (Jensen, 2003; Schweitzer, Ordonez, \& Douma, 2004), and reduced helping behavior (Wright, George, Farnsworth, \& McMahan, 1993). In addition, Ordonez et al. (2009) argued that 'the very presence of goals may lead employees to focus myopically on shortterm gains and lose sight of the potential devastating long-term effects on the organization' (p. 8). These mixed consequences may suggest that the impact of goals is likely to be contingent on the particular information that is communicated by the goal content (Locke \& Latham, 2009).

Unfortunately, the complexity of organizations suggests that there will be many instances when goal content is not fully or clearly specified, such as when goals only emphasize one type of task performance at the expense of others, or when multiple potentially conflicting goals are in play. Thus, behavioral norms and expectations would be unclear or ambiguous for people. In such situations when goals do not offer clear guidelines on behavioral expectations, we draw on the group-value model (Lind \& Tyler, 1988; Tyler \& Lind, 1992) and the uncertainty management model (e.g., Van den Bos \& Lind, 2002) to argue that procedural justice can be used as a signal for informing employees of whether they should voluntarily expand their job boundaries to conduct proactive helping behaviors that enhance the group's well-being. Although a goal may be quite specific about the desired task performance, it may still lack information about integrity or ethical expectations, leaving employees to experience ambiguity with respect to ethical performance. In such situations, people may rely on information from their social context that they can use to effectively deal with uncertainty. Fairness-related information thus serves as a useful heuristic when an employee is missing a critical piece of information. For instance, fairness information has been used as a heuristic substitute to decide the trustworthiness of the authority when one does not have direct experience with that authority (Van den Bos, Wilke, \& Lind, 1998).

We thus propose that procedural justice should have the strongest effect on proactive preventive behavior (e.g., correcting coworker or supervisor deception) when goals convey uncertainty about such behavioral norms, such as goals focused on specific performance outcomes other than integrity of the content, nonspecific goals, or when multiple goals are assigned. However, when individuals receive goals focused on truth and accuracy of content, the norm with respect to proactively preventing wrong information to be released is already communicated and the informational value of procedural justice would therefore be reduced. In sum, we predict the following interaction of procedural justice and goal setting:

Hypothesis 2: Procedural justice will interact with goal assignment to influence proactive preventive behavior such that the positive relationship between procedural 
justice and proactive preventive behavior will be stronger when individuals are assigned (1) a goal focused on specific task performance other than truth and accuracy, or (2) a nonspecific 'do your best' goal, or (3) multiple goals, relative to when individuals are assigned goals focused on truth and accuracy.

In the following section, we present two studies designed to test the hypotheses developed earlier. In Study 1, we gave participants a brochure and manipulated goal content by assigning individuals a goal that was focused on grammar, or focused on truthfulness and accuracy of the content, or did not specify a particular aspect of task performance (i.e., 'do your best'), and we manipulated procedural justice to assess its direct and interactive effects on task revision. To further explore these relationships, Study 2 again used the brochure methodology but operationalized procedural justice as a measured (rather than manipulated) variable and introduced a new condition where uncertainty stemmed from having more than one goal assigned (i.e., both grammar and truthful content goals).

\section{Study 1}

\section{Method}

\section{Participants}

We recruited 206 undergraduate students from a management course at a large southern university to participate in our study. Participants were told that their participation in this study was voluntary, and confidentiality was guaranteed. Among the participants, 54 percent were female, 98 percent were between 19 and 22 years of age, and 91 percent were Caucasian. Participants received extra credit in their management course and received an opportunity to win a $\$ 100$ lottery prize for participating in this study. Participants were told that they would be given lottery tickets for the $\$ 100$ prize after participating in the study, but the number of lottery tickets that they received would be based on their performance in the study (i.e., higher levels of performance would result in more lottery tickets and a greater chance to win the $\$ 100$ ).

\section{Procedures}

The study was conducted in two phases. In the first phase, participants were asked to complete an online questionnaire that contained control variables and other individual difference variables unrelated to the current study. After approximately 1 month, the participants who completed phase one were asked to participate in the second phase in a laboratory. They were then given our stimulus materials and were asked to edit a paragraph in a promotional brochure about the university that they attended. Our promotional brochure was based on the one used by Staw and Boettger (1990) with information in the brochure adjusted in order to be consistent with the current university.

We conducted a 2 (procedural fairness: low or high) $\times 3$ (goal setting: grammar goal, truthful content goal, or nonspecific goal) factorial design. Participants were randomly assigned to one of the six conditions. Upon entering the laboratory, they were told:

We are preparing a promotional brochure to recruit high school students across the nation to [university name] and we need some help with the preparation of this brochure (i.e., assistance with editing the brochure).

The researcher then first asked participants to answer an initial set of questions unrelated to the present study. At this time, a different researcher entered the room and executed the justice manipulation. During the initial sign-up of this study, participants were told that the extra credit for their management class was conditional on participating in two 1-hour phases of a study. In the high procedural fairness condition $(N=99)$, participants were given information consistent with what they were told previously (i.e., that they would need to participate in two phases to receive extra credit). 
However, in the low procedural fairness condition $(N=107)$, participants were given inconsistent information. In particular, these participants were told that they would have to participate in a third phase before they would receive extra credit. Consistency is one of the six procedural justice criteria outlined by Leventhal, Karuza, and Fry (1980), and corresponds with one of the items used by Colquitt (2001) to measure procedural justice (i.e., 'To what extent have those procedure been applied consistently?'). Following phase two, all participants were told in a debriefing session that there would be no additional phases and they all received the same amount of extra credit.

Next, participants were given a one-page fact sheet with background information about the university. This fact sheet, as described below, provided information for editing the brochure and refuted five untrue statements that served as our measure of proactive preventive behavior. Participants had 2 minutes to read the fact sheet, and were allowed to look back at this fact sheet during the rest of the study.

Next, participants received the goal-setting manipulation. The grammar goal was operationalized using a goal that focused participants' attention on only one aspect of the task: correcting the grammar of the brochure. Specifically, participants assigned to this condition $(N=65)$ were told to 'pay attention to transitions, subject-verb agreement, correct diction, and syntax - all those grammar errors we were taught at school but rarely practiced. Please correct all 5 grammar errors. Try to achieve this goal in your revision.' Also, they were told that there were ten errors in total in the brochure, five of which were grammar errors.

The truthful content goal was operationalized using a goal that focused participants' attention on correcting untruthful statements. We augmented Staw and Boettger's (1990) accuracy language to include truthfulness and honesty in the goal instructions. Specifically, participants assigned to this condition $(N=68)$ were told to 'pay attention to making sure that the paragraphs portray an accurate picture of being a student here in [university's city]. We want to be sure that the information honestly portrays [university name]. Please correct all 5 untruthful statements. Try to achieve this goal in your revision.' As in the grammar goal condition, they were told that there were ten errors in total, five of which were untruthful statements.

The participants assigned to the nonspecific goal condition $(N=73)$ were told to make any changes necessary to improve the promotion brochure. They were told: 'Please read the following section from the promotional brochure. We think it needs some work. You can make any changes you wish.' Appendix 1 includes a complete list of the brochure errors, which contained five grammar mistakes and five untrue statements about the university and the town in which it is located.

\section{Dependent variable}

Proactive preventive behavior was measured as the number of corrections made to the factual content of the promotional brochure (e.g., Staw \& Boettger, 1990), with values ranging from 0 (no corrections) to 5 (all five untrue statements corrected). Importantly, the fact sheet clearly indicated that the five untrue statements were false statements. Moreover, the untrue statements in the brochure embellished or exaggerated aspects of the university and/or the town to persuade the reader to view the university in a more positive light. ${ }^{1}$ Three raters who were unaware of the experimental conditions and manipulations individually judged the number of untruthful statements identified by participants. Any disagreements subsequently were resolved by discussion and the raters reached complete consensus.

\section{Manipulation checks}

We included two sets of items to check whether our procedural justice manipulation was successful. First, we included two comprehension items to check that the students understood the

\footnotetext{
${ }^{1}$ We presented the brochure used in Study 1 to a separate sample of 25 undergraduate students at the same school where the studies were run to assess whether the five untrue statements were perceived as intentionally deceptive information. Results indicated that participants agreed that these statements were lies rather than true statements.
} 
procedural justice manipulation. These items were: 'I will need to participate in phase three to receive all 10 extra credit points' and 'I can receive all 10 extra credit points by the end of phase two.' Further, we used three items slightly modified from Colquitt's (2001) procedural justice measure and one additional item to verify that our manipulation influenced the participant's perceptions of procedural justice. An example was: 'Those procedures used in the experiment were applied consistently.' The fourth item was: 'The researchers used well-designed and -implemented methods to determine how outcomes such as lottery tickets were distributed' $(\alpha=0.79)$. In addition, we measured perceptions of distributive and interactional justice. ${ }^{2}$

To assess whether or not our goal-setting manipulations were successful, we asked participants to what extent they agreed with the following two statements: 'I was given directions to improve the grammar of the paragraph' and 'I was given directions to make the paragraph as truthful as possible to prospective students.' Participants responded to all manipulation check items on a 7 -point Likert scale $(1=$ strongly disagree, $7=$ strongly agree).

\section{Control variables}

We controlled for the following demographic information in this study: gender $(1=$ female; $2=$ male), year in school ( $1=$ freshman, $2=$ sophomore, $3=$ junior, and $4=$ senior $)$, and age $(1=$ under $18 ; 2=18 ; 3=19 ; 4=20 ; 5=21 ; 6=22 ; 7=23 ; 8=24 ; 9=25 ; 10=$ over 25$)$. In addition, using the Positive and Negative Affect Schedule (Watson, Clark, \& Tellegen, 1988), we controlled for negativity affectivity $(\alpha=0.85)$ because it has been shown to relate to employees' deviance directed toward their organization and coworkers (Aquino, Lewis, \& Bradfield, 1999). Using Aquino and Reed's (2002) 10-item moral identity scale $(\alpha=0.87)$, we controlled for selfimportance of moral identity because it could affect sensitivity to justice as a signal of moral and social norms.

Goal commitment was controlled as well because it has been found to be an important factor linking goals to performance (Locke \& Latham, 1990). After the goal was assigned, but before participants began revising the brochure, we measured participants' goal commitment using the 7 -item scale developed by Hollenbeck, Williams, and Klein (1989) $(\alpha=0.85)$.

Finally, we expected that students who more closely identified with the university would be likely to spend more effort correcting the paragraph. Organizational identification was measured by the inclusion of other in the self scale (Aron, Aron, \& Smollan, 1992), which is a single-item pictorial measure of individuals' interpersonal interconnectedness.

\section{Results}

\section{Manipulation checks}

We conducted analysis of variance tests to determine if our manipulations were successful. For our two-item procedural justice comprehension check, results showed that participants in the low procedural justice condition agreed more with the statement that they needed to participate in a third phase of the study to receive extra credit $(M=4.88, \mathrm{SD}=2.09)$ than in the high procedural justice condition $(M=1.30, \mathrm{SD}=0.73), F(1,187)=249.43, p \leq .05$; and participants in the high procedural justice condition agreed more with the statement that they would receive their extra credit at the end of the second phase $(M=6.78, \mathrm{SD}=0.63)$ than in the low procedural justice condition $(M=3.45, \mathrm{SD}=2.26), F(1,187)=189.35, p \leq .05$. Also, results on the 4 -item procedural justice scale showed that those participants in the high procedural justice condition

\footnotetext{
${ }^{2}$ Procedural justice has shown a stronger predicting power on organizational citizenship behaviors than other dimensions of justice (Moorman, Niehoff, \& Organ, 1993; Organ \& Moorman, 1993), but we included distributive and interactional justice items as a control in order to cleanly establish the effects of procedural justice. We assessed participants' distributive justice perceptions with the following items: 'The outcome reflects the effort I have put into the work,' 'The outcome is appropriate for the work I completed,' and 'Given my performance, my outcome is justified' ( $1=$ strongly disagree; $7=$ strongly agree). These items were averaged to create a distributive justice scale $(\alpha=0.92)$. We assessed interactional justice perceptions with the item: 'The experimenter treated me fairly' ( $1=$ strongly disagree; $7=$ strongly agree).
} 
$(M=4.97, \mathrm{SD}=1.08)$ perceived that the experimenters were more procedurally fair than in the low procedural justice condition $(M=4.67, \mathrm{SD}=0.85), F(1,187)=4.57, p \leq .05$. Importantly, the manipulation did not perturb perceptions of distributive justice in either conditions, $F$ (2, $205)=0.81$, n.s., or interactional justice, $F(2,205)=0.80$, n.s. Thus, these results indicated that our procedural justice manipulation worked as intended.

Both goal-setting manipulation checks demonstrated a significant main effect on our goalsetting independent variable, $F(2,187)=21.25, p \leq .05$ and $F(2,187)=22.30, p \leq .05$, respectively. Pairwise comparisons on these manipulation checks in the three goal-setting conditions indicated that participants in the grammar goal condition $(M=5.41, \mathrm{SD}=1.51)$ agreed more with the statement that they were given directions to improve the grammar of the paragraph than participants in the truthful content goal $(M=3.67, \mathrm{SD}=1.91$, mean difference $=1.76, \mathrm{SE}=0.32$, $p \leq .05)$ and nonspecific goal $(M=3.62, \mathrm{SD}=1.86$, mean difference $=1.80, \mathrm{SE}=0.31, p \leq .05)$ conditions. Also, participants in the truthful content goal condition $(M=5.35, \mathrm{SD}=1.32)$ agreed more with the statement that they were given directions to make the paragraph as truthful as possible than participants in the grammar goal $(M=3.38, \mathrm{SD}=1.87$, mean difference $=1.97$, $\mathrm{SE}=0.30, p \leq .05)$ and nonspecific goal $(M=3.97, \mathrm{SD}=1.78$, mean difference $=1.38, \mathrm{SE}=0.29$, $p \leq .05)$ conditions. Further, for these manipulation checks there were no significant procedural justice main effects or interactional effects. Therefore, these results indicated that our goal-setting manipulation was successful.

\section{Analysis}

We conducted analysis of covariance on proactive preventive behavior to test our hypotheses. Results are shown in Table 1. Consistent with Hypothesis 1, we found a main effect of procedural justice such that proactive preventive behavior was higher in the high $(M=1.66, \mathrm{SD}=1.21)$ rather than low $(M=1.35, \mathrm{SD}=1.17)$ procedural justice condition; $F(1,185)=3.78, p \leq .05$, $\eta^{2}=0.02$. Consistent with Hypothesis 2 , the main effect was qualified by a significant interaction between goal setting and procedural justice, $F(2,185)=2.96, p \leq .05, \eta^{2}=0.03$. Figure 1 plots this interaction.

To further examine this interactive effect, we conducted two analysis of covariances using the same controls as in the previous analysis and separating our sample by whether or not

Table 1. Analysis of covariance results for the effect of procedural justice on proactive preventive behavior in Study 1

\begin{tabular}{|c|c|c|c|}
\hline Variable & $d f$ & $F$ & $\eta^{2}$ \\
\hline Gender & 1,185 & 2.64 & 0.01 \\
\hline Age & 1,185 & $2.69^{\dagger}$ & 0.01 \\
\hline Year in school & 1,185 & 0.00 & 0.00 \\
\hline Negative affectivity & 1,185 & $4.98^{\star}$ & 0.03 \\
\hline Organizational identification & 1,185 & 0.71 & 0.00 \\
\hline Self-importance of moral identity & 1,185 & 0.22 & 0.00 \\
\hline Goal commitment & 1,185 & 0.01 & 0.00 \\
\hline Goal setting & 2,185 & $14.04^{\star \star}$ & 0.13 \\
\hline Procedural justice (factor) & 1,185 & $3.78^{\star}$ & 0.02 \\
\hline Goal setting $\times$ procedural justice & 2,185 & $2.96^{\star}$ & 0.03 \\
\hline
\end{tabular}




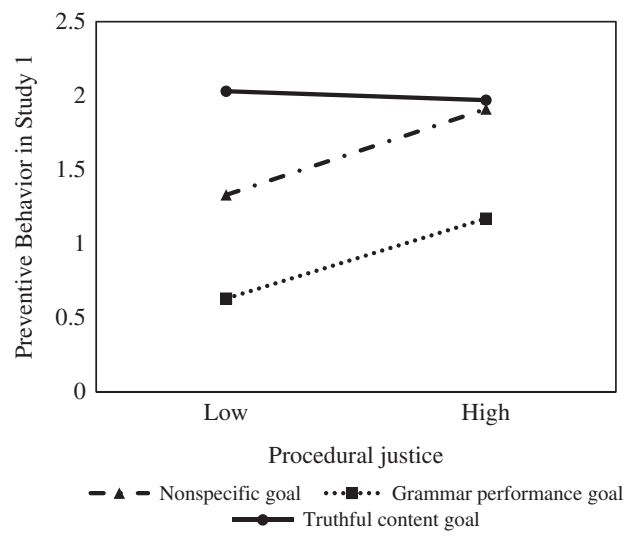

Figure 1. Interaction between goal setting and procedural justice (manipulated) on proactive

participants received a truthful content goal. The results indicated that procedural justice had a positive effect on proactive preventive behavior for those participants who received nonspecific or grammar performance goals, $F(1,122)=7.65, p \leq .01, \eta^{2}=0.06$, whereas procedural justice was not significantly related to proactive preventive behavior for those participants who received a truthful content performance goal, $F(1,58)=0.33, p>.10, \eta^{2}=0.01 .^{3}$

Though not focal to our investigation, we also note that there was a main effect of goal setting on proactive preventive behavior, $F(2,185)=14.04, p \leq .05, \eta^{2}=0.13$ (Table 1). Specifically, participants showed more proactive preventive behavior when assigned a truthful content performance goal $(M=1.94, \mathrm{SD}=1.09)$ than when assigned a grammar performance goal $(M=0.92$, $\mathrm{SD}=1.13)$, mean difference $=1.02, \mathrm{SE}=0.20, p \leq .05$, but not significantly different from the nonspecific goal condition $(M=1.65, \mathrm{SD}=1.14)$, mean difference $=0.29, \mathrm{SE}=0.19, p>.05$. This is consistent with past research (Staw \& Boettger, 1990).

\section{Discussion}

Overall, we found support for our prediction that procedural justice increases proactive preventive behavior, but only when a clear referent for engaging in such behavior is not otherwise specified. These findings support the group-value model of justice (e.g., Lind \& Tyler, 1988; Tyler \& Lind, 1992) by demonstrating that people use procedural fairness information to know their status and value in the group. When they feel they are highly valued group members, they will have increased identification with the group and would proactively perform the task to make the group better-off. Thus, procedural justice could increase their tendency to correcting the dishonest, potentially harmful, or morally unacceptable information created by others. Second, our findings suggest that procedural justice is a possible antidote for the emerging findings that goal setting, if not specified correctly, may encourage a problematically narrow attentional and behavioral focus (e.g., Staw \& Boettger, 1990; Shah \& Kruglanski, 2002; Ordonez et al., 2009). Our finding that procedural justice has a greater effect when goals convey uncertainty about the importance of integrity is also consistent with the uncertainty management model of justice (e.g., Van den Bos \& Lind, 2002).

\footnotetext{
${ }^{3}$ Because our dependent measure is a count variable, we also tested our hypotheses using Poisson regression with dummycoded variables included to indicate goal-setting condition. The Poisson results replicated the analysis of variance results. The analysis yielded a significant main effect of procedural justice $(B=0.22, p<.01)$ and a significant interaction between procedural justice and goal assignment $(B=-0.26, p<.05)$. Probing the significant interaction indicates that procedural justice had a positive effect on proactive preventive behavior for those participants who received a nonspecific or grammar goal $(B=0.21, p<.05)$, but procedural justice had no effect on those who received a truthful content goal $(B=-0.03$, n.s.).
} 
In the following study, we were interested in a situation where ambiguity stemmed from receiving goals that focused both on grammar and the truthfulness of the content. A dual goal condition is likely to more closely mirror real workplace situations where employees must juggle multiple priorities. Investigations of multiple simultaneous goals (e.g., Erez, Gopher, \& Arzi, 1990; Kernan \& Lord, 1990; Shalley, 1991; Locke, Smith, Erez, Chah, \& Schaffer, 1994; DeShon, Kozlowski, Schmidt, Milner, \& Wiechman, 2004) suggest that people tend to prioritize one goal or another in order to manage the conflicting nature of the task. Thus, we expect that the dual goal condition will create uncertainty for people in terms of which behavior is more valued, and procedural justice will significantly increase proactive preventive behaviors for those participants.

\section{Study 2}

\section{Method}

\section{Participants}

A total of 97 undergraduate students from a management course at a large southern university participated in the study. Participants were told that their participation was voluntary and confidentiality was guaranteed. Students received extra credit points in their management course for their participation. Among the participants, 43 percent were female, $89 \%$ were between 18 and 22 years of age, $86 \%$ were Caucasian, and $93 \%$ were native English speakers.

\section{Procedures}

The procedures and goal manipulations of Study 2 were similar to that of Study 1, again with two separate phases. The differences are noted below.

Participants were given the brochure revision task in Study 1. But in Study 2, we focused on three grammar mistakes and three untrue statements (grammar errors 1, 2, and 3 and untrue statements 1, 3, and 5 in Appendix 1).

Participants were randomly assigned to a grammar goal $(N=33)$ or truthful content goal $(N=35)$ condition, which were the same goal manipulations used in Study 1 . However, in Study 2 we introduced a different type of uncertain situation: a dual goal condition $(N=29)$ where both a grammar goal and a truthful content goal were assigned. Participants in the dual goal condition were told to 'pay attention to transitions, subject-verb agreement, correct diction, and syntax - all those grammar rules we were taught at school but rarely practiced. You also need to pay attention to making sure the brochure portrays an accurate picture of being a student here in [university's city] and honestly portrays [university name]. Please try to achieve these goals by catching 3 grammar errors and 3 untruthful statements in your revision, and mark any changes on the brochure.' The order of the presentation of the grammar and truthful content goal instructions within the brochure was randomized, and the results showed that the order of presentation had no effect.

Procedural justice was measured with Colquitt's (2001) 7-item scale. ${ }^{4}$ An example was: 'Those procedures used in the experiment were applied consistently' $(1=$ strongly disagree, $7=$ strongly agree; $\alpha=0.70)$.

\section{Dependent variable}

As with Study 1, our proactive preventive behavior-dependent variable focused on the sum of the untrue statements identified and corrected by participants, rated by three judges, with values ranging from 0 to 3 .

\footnotetext{
${ }^{4} \mathrm{We}$ originally intended to manipulate procedural justice by allowing individuals to voice their opinions in this study, but the manipulation was unsuccessful and had no effect on any of the justice manipulation checks, nor did the manipulation affect any other variable we collected. Therefore, we focused all analyses on the measured procedural justice scale. As a further conservative test, we re-ran all analyses in Table 2 controlling for the manipulation, but it still had no effect and did not change the results. Thus, it is dropped from all analyses reported here.
} 


\section{Manipulation checks}

To assess whether or not our goal-setting manipulations were successful, participants were asked to what extent they recognized the goal they were assigned. Participants in each condition responded to the statements: 'I corrected all of the grammar errors in the brochure,' and 'I corrected all of the untrue statements in the brochure' ( $1=$ strongly disagree; $7=$ strongly agree).

\section{Control variables}

We controlled for age $(1=$ under $18 ; 2=18 ; 3=19 ; 4=20 ; 5=21 ; 6=22 ; 7=23 ; 8=24 ; 9=25$; $10=$ over 25). In addition, whether participants were native English speakers $(1=$ native; $2=$ nonnative) was controlled for because contrary to Study 1, this sample includes both native and nonnative English speakers, which could affect comfort with grammatical edits. We also measured organizational identification and goal commitment $(\alpha=0.74)$ using the same items described in Study 1.

\section{Results}

\section{Manipulation checks}

We conducted planned pairwise comparisons of mean ratings on the goal comprehension manipulation checks. As expected, participants in the two conditions where a truthful content goal was assigned (i.e., the truthful content goal condition and the dual goal condition) agreed more with the statement 'I corrected all of the untrue statements in the brochure' $(M=5.00$, $\mathrm{SD}=1.24)$ than participants who were only assigned a grammar goal $(M=4.24, \mathrm{SD}=1.80), F(1$, $93)=5.77, p<.05$. Participants in the two conditions where a grammar goal was assigned (i.e., the grammar goal condition and dual goal condition) agreed more with the statement 'I corrected all of the grammar errors in the brochure' $(M=4.72, \mathrm{SD}=1.34)$ than participants who were only assigned a truthful content goal $(M=4.17, \mathrm{SD}=1.56), F(1,93)=3.23, p<.05$ (one-tailed).

\section{Analysis}

We conducted analysis of covariance on proactive preventive behavior to test our hypotheses. Consistent with our hypotheses, results in Table 2 demonstrated a significant main effect of procedural justice, $F(1,83)=12.30, p<.01, \eta^{2}=0.13$. In addition, there was an interaction between goal setting and procedural justice, $F(2,83)=3.29, p<.05, \eta^{2}=0.07$.

To further examine the interactive effects between goal setting and procedural justice, we conducted three analysis of covariances using the same controls as in the previous analysis and separating our sample by whether or not the participants received a truthful content goal, a grammar goal, or both goals. As predicted and illustrated in Figure 2, the results indicated that

Table 2. Analysis of covariance results of the effect of procedural justice on proactive preventive behavior in Study 2

\begin{tabular}{|c|c|c|c|}
\hline Variable & $d f$ & $F$ & $\eta_{\mathrm{p}}^{2}$ \\
\hline Age & 1,83 & 1.71 & 0.02 \\
\hline Native English speaker & 1,83 & 0.20 & 0.00 \\
\hline Goal commitment & 1,83 & 0.20 & 0.00 \\
\hline Organizational identification & 1,83 & 0.01 & 0.00 \\
\hline Goal setting & 2,83 & $4.27^{\star}$ & 0.09 \\
\hline Procedural justice (scale) & 1,83 & $12.30^{\star \star}$ & 0.13 \\
\hline Goal setting $\times$ procedural justice & 2,83 & $3.29 *$ & 0.07 \\
\hline
\end{tabular}




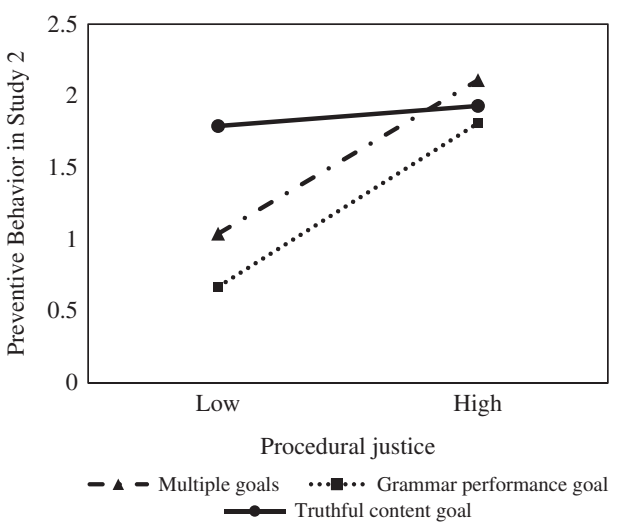

Figure 2. Interaction between goal setting and procedural justice (measured) on proactive preventive behavior in Study 2

procedural justice had a positive effect on proactive preventive behavior for those participants who received a grammar goal, $B=0.71, \mathrm{SE}=0.22, t=3.28, p \leq .01, \eta^{2}=0.29$; or both goals together, $B=0.59, \mathrm{SE}=0.27, t=2.16, p \leq .05, \eta^{2}=0.18$. But procedural justice was not significantly related to proactive preventive behavior for those participants who received a truthful content goal, $B=0.08, \mathrm{SE}=0.21, t=0.36, p>.10, \eta^{2}=0.01 .^{5}$

\section{Discussion}

Study 2 replicates and extends our findings from Study 1, demonstrating once again that procedural justice predicts proactive preventive behavior for situations where behavioral values and norms are ambiguous or uncertain, but that the presence of a goal that makes norms salient attenuates the effects of procedural justice. This study builds on the previous study by utilizing a different operational definition of procedural justice, and by including a mixed goal condition that provided a different source of uncertainty than was evident in Study 1. Indeed, the results of Study 2 suggest that providing multiple goals can result in similar effects as providing no goal at all, whereby in both cases the participant is potentially unsure of what is more valued by the organization and hence relies on procedural justice as a cue to engage in proactive preventive behavior. It is only when employees are given specific information that mis-statements need to be corrected will the function of procedural justice be reduced.

\section{General Discussion}

Across two experiments, we consistently found that procedural justice has a positive effect on employees' proactive preventive behaviors, specifically, in the form of task revision. In addition, procedural justice interacts with goal setting to predict proactive preventive behavior, such that the relationship between procedural justice and proactive preventive behavior was stronger when individuals were assigned (1) goals specifically focused on aspects of performance other than truth and accuracy, (2) nonspecific goals, or (3) multiple goals, relative to when individuals were assigned goals explicitly focused on truthfulness of content.

\footnotetext{
${ }^{5}$ We re-ran all analyses using Poisson regression due to the count-dependent variable, and the results were consistent with the analysis of variance. There was a significant main effect of procedural justice $(B=0.28, p<.05)$ and a significant interaction between procedural justice and goal assignment $(B=0.46, p<.05)$. Procedural justice had a positive effect on proactive preventive behavior for those participants who received a grammar goal $(B=0.65, p<.01)$ or dual goals $(B=0.40$, $p<.05$, one-tailed), but procedural justice had no effect on those who received a truthful content goal $(B=0.03$, n.s.).
} 


\section{Theoretical contributions}

The current study contributes to employees' extra-role behavior at the workplace, especially their proactive preventive behavior. Organizations often try to encourage employee's proactive promotive behaviors, but their preventive behaviors are at least equally important and protect individuals within the organization from engaging in erroneous behaviors. The current study enriches our understanding on when employees would be likely to engage in such proactive preventive behaviors. Second, our findings speak to organizational justice scholars interested in group-value model (e.g., Lind \& Tyler, 1988; Tyler \& Lind, 1992) and the uncertaintymanagement model (e.g., Van den Bos \& Lind, 2002) by providing some preliminary evidence for the proactive performance benefits of acting in a procedurally fair manner, particularly when the job requirement is otherwise uncertain. We extended Staw and Boettger's (1990) work and showed that procedural justice can act as a normative cue in situations where people are given multiple goals, vague (nonspecific) goals, or when other task expectations are specified but not truthfulness or accuracy.

Moreover, the capacity for procedural justice to offset the negative influence of narrowly specified goals on proactive preventive behavior contributes to the literature on the mixed effects of performance goals, which tend to focus people's attention on one narrow aspect of a task while shielding attention from other important aspects of the task (e.g., Locke \& Bryan, 1969; Kanfer \& Ackerman, 1989; Staw \& Boettger, 1990; Shah \& Kruglanski, 2002), including ethical considerations (Schweitzer, Ordonez, \& Douma, 2004; Barsky, 2008; Ordonez et al., 2009). Thus, we further advance Staw and Boettger's (1990) work, which only discussed the undesirable effects of goal setting.

\section{Managerial implications}

If managers wish to promote proactive preventive behavior, then our results suggest that such behavior is at its best when a performance goal that emphasizes integrity or quality assurance is assigned, or if an ambiguous goal or multiple goals are assigned and procedurally fair treatment is perceived at the same time. Without the interactive effect of procedural justice and goal setting, our work may have troubling implications for managers, with task performance goals hindering proactive preventive behavior (e.g., ethical performance). This tradeoff between economic performance or productivity and other functional behaviors (such as proactive preventive behavior) is an unavoidable aspect of organizational life (Staw \& Boettger, 1990; Wright et al., 1993), and 'the dilemma for organizations is managing the tension between business needs and ethical actions' (Gottlieb \& Sanzgiri, 1996: 1276). The interactive effect of procedural justice and goal setting, however, implies that, by treating employees in a procedurally fair manner, organizations may increase such functional behaviors even when other necessary task-oriented goals are set.

\section{Limitations and opportunities for future research}

Our findings must be viewed in light of the limitations of our study. First, despite the causal evidence afforded by data derived from experimental research, the generalizability of our findings is limited. Our findings need to be validated in future field studies.

Second, our investigation on proactive preventive behavior involves the correction of deception, which is a behavior that arguably has potential ethical implications. However, we focused on a relatively narrow criterion. Although we chose to focus specifically on correcting untrue/inaccurate statements which may mislead readers of the brochure, it may be fruitful to investigate whether the compensatory influence of procedural justice and goal setting holds for other overtly ethical behaviors such as constructive deviance (e.g., Warren, 2003) and whistleblowing (Miceli \& Near, 1992; Gundlach, Douglas, \& Martinko, 2003). We expect that theoretically those studies should show similar relationships as reported here. Thus far, justice researchers have investigated the negative relationship between organizational justice and primarily deviant behavior (e.g., Greenberg, 2002), whereas only a handful of studies (e.g., 
Treviño \& Weaver, 2001) examined the positive relationship between procedural justice and ethical behavior. Our findings tentatively suggest that fair treatment might potentially increase ethical behavior, though future work should more explicitly investigate this relationship to determine if these findings generalize to various forms of proactive ethical behavior (e.g., voluntarily reporting flaws in a product or service) and other forms of organizational justice (e.g., distributive and interactional justice).

Third, we manipulated procedural justice in Study 1 on one of the six Leventhal et al.'s (1980) criteria, namely, consistency. Although previous research usually manipulated procedural justice on a particular criteria (e.g., Greenberg, 1987; Lind, Kanfer, \& Earley, 1990; Van Prooijen, Van den Bos, \& Wilke, 2002), it has to be noted that this is a rather restrictive manipulation. Future research that replicates our findings with procedural justice manipulation on other criteria is encouraged. Realizing this limitation, in our Study 2, we operationalize procedural justice with Colquitt's (2001) 7-item scale, instead of manipulating it. This may mitigate this particular limitation.

Another ripe area for future research would be to test the compensatory influence of justice and goal setting by examining fundamentally different types of goals. Our work suggests that procedural justice can offset the tendency for some types of performance goals to cause individuals to construe their tasks too narrowly. It would be valuable to consider how goals focused on learning, rather than performance (e.g., Kanfer \& Ackerman, 1989; Seijts \& Latham, 2005), might interact with justice to determine proactive preventive behavior and other counter-role or prosocial behaviors. Learning-oriented goals focus attention on acquiring knowledge and developing strategies, thus encouraging processing information more broadly. From the perspective of the current investigation, learning-oriented goals might also promote more task revision relative to performance-oriented goals, since learning-goals are not focused on an end result. Therefore, the compensatory effect of procedural justice on learning goals might be reduced. We encourage future research to examine this possibility.

Last but not the least, the group-value model suggests that when people perceive procedural fairness, they identify more with the group (Tyler, 1989). According to the literature on group identification, the more members identify with a group, the more likely they would follow the group norm instead of challenging it (Hogg, 1992; Hogg \& Hains, 1996; Hogg \& Terry, 2000). But meanwhile, when members identify with the group, they would also volunteer helping behaviors to make the group better (e.g., Colquitt, Conlon, Wesson, Porter, \& Ng, 2001). In the current research, we follow the latter argument and do find a direct effect from procedural justice to proactive preventive behavior, but it does not fully rule out the other possibility. Future research is needed to investigate the contextual and personal factors that may trigger one particular mechanism.

\section{Conclusion}

Proactive preventive behavior needs more attention from both researchers and practitioners. Using two experiments, we showed that procedural justice could increase such desirable behaviors from employees. In addition, we also find that procedural justice may provide a possible antidote to compensate for the downsides of narrowly focused goals. Moreover, procedural justice facilitates proactive performance primarily in situations where there is uncertainty surrounding organizational values and norms (i.e., when goals are not specific, or when multiple goals are assigned). Thus, procedural justice can be combined with performance goals to reap the valuable aspects of goal setting while minimizing some of the unwanted side effects.

Acknowledgement. The authors would like to thank Dr. Elizabeth E. Umphress and Dr. Bradley L. Kirkman for their valuable comments on early versions of this study.

\section{References}

Aquino, K., Lewis, M. U., \& Bradfield, M. (1999). Justice constructs, negative affectivity, and employee deviance: A proposed model and empirical test. Journal of Organizational Behavior, 20, 1073-1091. 
Aquino, K. F., \& Reed, A. II (2002). The self-importance of moral identity. Journal of Personality and Social Psychology, 83, 1423-1440.

Aron, A., Aron, E. N., \& Smollan, D. (1992). Inclusion of other in the self scale and the structure of interpersonal closeness. Journal of Personality and Social Psychology, 63, 596-612.

Ashford, S. J., Blatt, R., \& VandeWalle, D. (2003). Reflections on the looking glass: A review of research on feedback-seeking behavior in organizations. Journal of Management, 29, 773-799.

Ashford, S. J., \& Cummings, L. L. (1983). Feedback as an individual resource: Personal strategies of creating information. Organizational Behavior and Human Performance, 32, 370-398.

Ashford, S. J., \& Cummings, L. L. (1985). Proactive feedback seeking: The instrumental use of the information environment. Journal of Occupational Psychology, 58, 67-79.

Barsky, A. (2008). The ethical cost of organizational goal setting. Journal of Business Ethics, 81, 63-81.

Borman, W. C., \& Motowidlo, S. J. (1993). Expanding the criterion domain to include elements of contextual performance. In N. Schmitt, \& W. C. Borman (Eds.), Personnel Selection, 71-98. San Francisco: Josey-Bass.

Brickey, K. F. (2003). From Enron to WorldCom and beyond: Life and crime after Sarbanes-Oxley (June 1, 2003). Washington University Law Quarterly, 81, 357-401.

Brockner, J., Tyler, T. R., \& Cooper-Schneider, R. (1992). The influence of prior commitment to an institution on reactions to perceived unfairness: The higher they are, the harder they fall. Administrative Science Quarterly, 37, 241-261.

Cole, R. E. (2011). What really happened to Toyota? MIT Sloan Management Review. http://sloanreview.mit.edu/themagazine/2011-summer/52417/what-really-happened-to-toyota/.

Colquitt, J. A. (2001). On the dimensionality of organizational justice: A construct validation of a measure. Journal of Applied Psychology, 86, 386-400.

Colquitt, J. A., Conlon, D. E., Wesson, M. J., Porter, C. O., \& Ng, K. Y. (2001). Justice at the millennium: a meta-analytic review of 25 years of organizational justice research.

Conlon, D. E. (1993). Some tests of the self-interest and group-value models of procedural justice: Evidence from an organizational appeal procedure. Academy of Management Journal, 36, 1109-1124.

DeShon, R. P., Kozlowski, SW. J., Schmidt, A. M., Milner, K. R., \& Wiechman, D. (2004). A multiple-goal, multilevel model of feedback effects on the regulation of individual and team performance. Journal of Applied Psychology, 89, $1035-1056$.

Dutton, J., \& Ashford, S. (1993). Selling issues to top management. Academy of Management Review, 18, 397-428.

Erez, M., Gopher, D., \& Arzi, N. (1990). Effects of goal difficulty, self-set goals, and monetary rewards on dual task performance. Organizational Behavior and Human Decision Processes, 47, 247-269.

Fay, D., \& Frese, M. (2001). The concept of personal initiative: An overview of validity studies. Human Performance, 14, 97-124.

Fay, D., \& Sonnentag, S. (2002). Rethinking the effects of stressors: A longitudinal study on personal initiative. Journal of Occupational Health Psychology, 7, 221-234.

Festinger, L. (1954). A theory of social comparison processes. Human Relations, 7, 117-140.

Frese, M., \& Fay, D. (2001). Personal initiative: An active performance concept for work in the 21 st century. In B. M. Staw, \& R. I. Sutton (Eds.), Research in organizational behavior, Vol. 23, pp. 133-187. Amsterdam: Elsevier Science.

Fritz, C., \& Sonnentag, S. (2009). Antecedents of day-level proactive behavior: A look at job stressors and positive affect during the workday. Journal of Management, 35(1), 94-111.

Gottlieb, J. Z., \& Sanzgiri, J. (1996). Towards an ethical dimension of decision making in organizations. Journal of Business Ethics, 15, 1275-1285.

Grant, A. M. (2007). Relational job design and the motivation to make a prosocial difference. Academy of Management Review, 32, 393-417.

Grant, A. M., \& Ashford, S. J. (2008). The dynamics of proactivity at work. Research in Organizational Behavior, 28, 3-34.

Greenberg, J. (1987). Reactions to procedural injustice in payment distributions: Do the ends justify the means? Journal of Applied Psychology, 72, 55-61.

Greenberg, J. (2002). Who stole the money, and when? Individual and situational determinants of employee theft. Organizational Behavior and Human Decision Processes, 91, 985-1003.

Griffin, R. W. (1987). Toward an integrated theory of task design. Research in Organizational Behavior, 9, 79-120.

Gundlach, M. J., Douglas, S. C., \& Martinko, M. J. (2003). The decision to blow the whistle: A social information processing network. Academy of Management Review, 28, 107-123.

Hogg, M. A. (1992). The social psychology of group cohesiveness: From attraction to social identity. UK: Harvester Wheatsheaf.

Hogg, M. A., \& Hains, S. C. (1996). Intergroup relations and group solidarity: Effects of group identification and social beliefs on depersonalized attraction. Journal of Personality and Social Psychology, 70(2), 295-309.

Hogg, M. A., \& Terry, D. I. (2000). Social identity and self-categorization processes in organizational contexts. Academy of Management Review, 25(1), 121-140.

Hollenbeck, J. R., Williams, C. R., \& Klein, H. J. (1989). An empirical examination of the antecedents of commitment to difficult goals. Journal of Applied Psychology, 74, 18-23. 
Jensen, M. C. (2003). Paying people to lie: The truth about the budgeting process. European Financial Management, 9, 379-406.

Kanfer, R., \& Ackerman, P. (1989). Motivation and cognitive abilities: An integrative/aptitude-treatment interaction approach to skill acquisition. Journal of Applied Psychology, 74, 657-690.

Kernan, M. C., \& Lord, R. G. (1990). Effects of valence, expectancies, and goal-performance discrepancies in single and multiple goal environments. Journal of Applied Psychology, 75, 194-203.

Knight, D., Durham, C. C., \& Locke, E. A. (2001). The relationship of team goals, incentives, and efficacy to strategic risk, tactical implementation, and performance. Academy of Management Journal, 44, 326-338.

Kuvaas, B., Buch, R., \& Dysvik, A. (2016). Performance management: Perceiving goals as invariable and implications for perceived job autonomy and work performance. Human Resource Management, 55, 401-412.

Larrick, R. P., Heath, C., \& Wu, G. (2009). Goal-induced risk taking in negotiation and decision making. Social Cognition, 27, 342-364.

LePine, J. A., \& Van Dyne, L. (2001). Voice and cooperative behavior as contrasting forms of contextual performance: Evidence of differential relationships with Big Five personality characteristics and cognitive ability. Journal of Applied Psychology, 86, 326-336.

Leventhal, G. S., Karuza, J., \& Fry, W. R. (1980). Beyond fairness: A theory of allocation preferences. In G. Mikula (Ed.), Justice and social interaction, 167-218. New York: Springer-Verlag.

Liang, J., Farh, CI. C., \& Farh, J. L. (2012). Psychological antecedents of promotive and prohibitive voice: A two-wave examination. Academy of Management Journal, 55, 71-92.

Lind, E. A., Kanfer, R., \& Earley, P. C. (1990). Voice, control, and procedural justice: Instrumental and noninstrumental concerns in fairness judgments. Journal of Personality and Social Psychology, 59(5), 952-959.

Lind, E. A., \& Tyler, R. R. (1988). The social psychology of procedural justice. New York: Plenum Press.

Locke, E. A., \& Bryan, J. E. (1969). The directing function of goals in task performance. Organizational Behavior and Human Performance, 4, 35-42.

Locke, E. A., \& Latham, G. P. (1984). Goal setting: A motivational technique that works!. Englewood Cliffs: Prentice Hall. Locke, E. A., \& Latham, G. P. (1990). A theory of goal setting and task performance. Englewood Cliffs, NJ: Prentice-Hall.

Locke, E. A., \& Latham, G. P. (2009). Has goal setting gone wild, or have its attackers abandoned good scholarship? Academy of Management Perspectives, 23, 17-23.

Locke, E. A., Smith, K. G., Erez, M., Chah, D., \& Schaffer, A. (1994). The effects of intra-individual goal conflict on performance. Journal of Management, 20, 67-91.

Miceli, M., \& Near, J. (1992). Blowing the whistle: The organizational and legal implications for companies and employees. New York: Lexington Books.

Moorman, R. H., Blakely, G. L., \& Niehoff, B. P. (1998). Does perceived organizational support mediate the relationship between procedural justice and organizational citizenship behavior? Academy of Management Journal, 41(3), 351-357.

Moorman, R. H., Niehoff, B. P., \& Organ, D. W. (1993). Treating employees fairly and organizational citizenship behavior: Sorting out the effects of job satisfaction, organizational commitment, and procedural justice. Employee Responsibilities and Rights Journal, 6, 209-225.

Morrison, E. W. (2006). Doing the job well: An investigation of pro-social rule breaking. Journal of Management, 32, 5-28.

Morrison, E. W. (2011). Employee voice behavior: Integration and directions for future research. Academy of Management Annals, 5, 373-412.

Nicholson, N. (1984). A theory of work role transitions. Administrative Science Quarterly, 29, 172-191.

O'Reilly, C. H., \& Chatman, J. (1986). Organizational commitment and psychological attachment: The effects of compliance, identification, and internalization on prosocial behavior. Journal of Applied Psychology, 71, 492-499.

Ordonez, L. D., Schweitzer, M. E., Galinsky, A. D., \& Bazerman, M. H. (2009). Goals gone wild: The systematic side effects of overprescribing goal setting. Academy of Management Perspectives, 23, 6-16.

Organ, D. W., \& Moorman, R. H. (1993). Fairness and organizational citizenship behavior: What are the connections? Social Justice Research, 6, 5-18.

Organ, D. W., \& Ryan, K. (1995). A meta-analytic review of attitudinal and dispositional predictors of organizational citizenship behavior. Personnel Psychology, 48, 775-802.

Parker, S. K. (2000). From passive to proactive motivation: The importance of flexible role orientations and role breadth selfefficacy. Applied Psychology: An International Review, 49, 447-469.

Parker, S. K., \& Collins, C. G. (2010). Taking stock: Integrating and differentiating multiple proactive behaviors. Journal of Management, 36, 633-662.

Parker, S. K., Williams, H. M., \& Turner, N. (2006). Modeling the antecedents of proactive behavior at work. Journal of Applied Psychology, 91, 636-652.

Rappaport, L., \& Rapoport, M. (2010). Ernst accused of Lehman Whitewash. The Wall Street Journal, 21, 2010-2201. http:// online.wsj.com/article/SB10001424052748704259704576033540546160536.html.

Restubog, S. L., Hornsey, M. J., Bordia, P., \& Esposo, S. R. (2008). Effects of psychological contract breach on organizational citizenship behaviour: Insights from the group value model. Journal of Management Studies, 45, 1377-1400. 
Rioux, S. M., \& Penner, L. A. (2001). The causes of organizational citizenship behavior: A motivational analysis. Journal of Applied Psychology, 86, 1306-1314.

Schweitzer, M., Ordonez, L. D., \& Douma, B. (2004). The dark side of goal setting: The role of goals in motivating unethical behavior. Academy of Management Journal, 47, 422-432.

Seijts, G. H., \& Latham, G. P. (2005). Learning versus performance goals: When should each be used? Academy of Management Executive, 19, 124-131.

Shah, J. Y., \& Kruglanski, A. W. (2002). Priming against your will: How accessible alternatives affect goal pursuit. Journal of Experimental Social Psychology, 38, 363-383.

Shalley, C. E. (1991). Effects of productivity goals, creativity goals, and personal discretion on individual creativity. Journal of Applied Psychology, 76, 179-185.

Shantz, A., \& Latham, G. (2011). The effect of primed goals on employee performance: Implications for human resource management. Human Resource Management, 50, 289-299.

Sims, R. L., \& Keenan, J. P. (1998). Predictors of external whistleblowing: Organizational and intrapersonal variables. Journal of Business Ethics, 17(4), 411-421.

Sonnentag, S. (2003). Recovery, work engagement, and proactive behavior. A new look at the interface between non-work and work. Journal of Applied Psychology, 88, 518-528.

Spector, P. E., \& Fox, S. (2002). An emotion-centered model of voluntary work behavior: Some parallels between counterproductive work behavior and organizational citizenship behavior. Human Resource Management Review, 12, 269-292.

Staw, B. M., \& Boettger, R. D. (1990). Task revision: A neglected form of work performance. Academy of Management Journal, 33, 534-559.

Tajfel, H. (1978). Differentiation between social groups. London: Academic Press.

Tajfel, H., \& Turner, J. (1986). The social identity theory of intergroup behavior. In S. Worchel (Ed.), Psychology of intergroup relations, 33-47. Chicago: Nelson-Hall.

Thibaut, J., \& Walker, L. (1975). Procedural justice: A psychological analysis. Hillsdale, NJ: Erlbaum.

Treviño, L. K., \& Weaver, G. R. (2001). Organizational justice and ethics program 'follow-through': Influences on employees' harmful and helpful behavior. Business Ethics Quarterly, 11, 651-672.

Tyler, T. R. (1989). The psychology of procedural justice: A test of the group-value model. Journal of Personality and Social Psychology, 57, 830-838.

Tyler, T. R., \& Blader, S. (2000). Cooperation in groups: Procedural justice, social identity and behavioral engagement. Philadelphia, PA: Psychology Press.

Tyler, T. R., \& Degoey, P. (1995). Collective restraint in social dilemmas: Procedural justice and social identification effects on support for authorities. Journal of Personality and Social Psychology, 69, 482-497.

Tyler, T., Degoey, P., \& Smith, H. (1996). Understanding why the justice of group procedures matters: A test of the psychological dynamics of the group-value model. Journal of Personality and Social Psychology, 70, 913-930.

Tyler, T. R., \& Lind, E. A. (1992). A relational model of authority in groups. Advances in Experimental Social Psychology, 25, 115-191.

Van den Bos, K., \& Lind, E. A. (2002). Uncertainty management by means of fairness judgments. In M. P. Zanna (Ed.), Advances in experimental social psychology (Vol. 34, pp. 1-60). San Diego, CA: Academic Press.

Van den Bos, K., Wilke, HA. M., \& Lind, E. A. (1998). When do we need procedural fairness? The role of trust in authority. Journal of Personality and Social Psychology, 75, 1449-1458.

Van Dyne, L., Cummings, L. L., \& Parks, J. M. (1995). Extra-role behaviors: In pursuit of construct and definitional clarity (a bridge over muddied waters). In LL Cummings, \& BM Staw (Eds.), Research in organizational behavior, 17, $215-285$. Greenwich, CT: JAI Press.

Van Prooijen, J. W., Van den Bos, K., \& Wilke, H. A. (2002). Procedural justice and status: Status salience as antecedent of procedural fairness effects. Journal of Personality and Social Psychology, 83(6), 1353-1361.

Warren, D. E. (2003). Constructive and destructive deviance in organizations. Academy of Management Review, 28, 622-632.

Watson, D., Clark, L. A., \& Tellegen, A. (1988). Development and validation of brief measures of positive and negative affect: The PANAS scales. Journal of Personality and Social Psychology, 54, 1063-1070.

Wright, P. M., George, J. M., Farnsworth, S. R., \& McMahan, G. (1993). Productivity and extra-role behavior: The effects of goals and incentives on spontaneous helping. Journal of Applied Psychology, 78, 374-381.

Wrzesniewski, A., \& Dutton, J. (2001). Crafting a job: Employees as active crafters of their work. Academy of Management Review, 26, 179-201.

Yang, J., Mossholder, K. W., \& Peng, T. K. (2009). Supervisory procedural justice effects: The mediating roles of cognitive and affective trust. The Leadership Quarterly, 20(2), 143-154. 


\section{Appendix 1}

Grammar Errors and Untrue Statements within the Promotional Brochure

\section{$\underline{\text { Grammar Errors }}$}

1. [University name], the state's first public institution of higher education, was openly on [date when it opened] as the [original university name].

2. In[date when the name changed], the name of the institution were changed to [university name] to more accurately reflect its expanding role as a leader in teaching, research, and public service for the state, nation, and world.

3. Originally, the initials [first initial] and [second initial] represent [first word in the university's name] and [second work in the university's name].

4. [University name] have now become a land-grant, sea-grant, and space-grant institution located in [university's city].

5. [University name] are a good place for being an undergraduate student for several reasons.

\section{Untrue Statement Errors}

1. The university's enrollment totals approximately [enrollment] students studying for degrees in 10 academic colleges, and the school has the most diverse student population in the [university's state].

2. [University's city] has a big city feel to it and is considered a metropolitan city by many people.

3. The city is centrally located, being approximately 30 minutes from four of the 10 largest cities in the United States ([three cities more than 60 miles from the university's city]) and the state capital ([the state capital in which the university is located]).

4. The university also has the best public transportation system operating on and off campus among the universities in the nation.

5. Furthermore, the school waives tuition for both domestic and international students.

NOTE: The underlined regions of the above text are the errors within the promotion brochure.

Cite this article: Ren R, Simmons AL, Barsky A, See KE and Gogus CI. 2018. It's not my job: Compensatory effects of procedural justice and goal setting on proactive preventive behavior. Journal of Management \& Organization X: 1-19, doi:10.1017/jmo.2018.69 